\title{
Pre-release hunting training and post-release monitoring are key components in the rehabilitation of orphaned large felids
}

\author{
AnnMarie Houser ${ }^{1,2 *}$, Markus Gusset ${ }^{3}$, Christy J. Bragg ${ }^{4}$, \\ Lorraine K. Boast ${ }^{1}$ \& Michael J. Somers ${ }^{2,5}$ \\ ${ }^{1}$ Cheetah Conservation Botswana, Gaborone, Botswana \\ ${ }^{2}$ Centre for Wildlife Management, University of Pretoria, Pretoria, 0002 South Africa \\ ${ }^{3}$ Wildlife Conservation Research Unit, Department of Zoology, University of Oxford, Abingdon OX13 5QL, U.K. \\ ${ }^{4}$ Department of Zoology, University of Cape Town, Rondebosch, 7701 South Africa \\ ${ }^{5}$ Centre for Invasion Biology, University of Pretoria, Pretoria, 0002 South Africa \\ Received 13 July 2010. Accepted 6 April 2011
}

\begin{abstract}
The rehabilitation of orphaned animals is commonly practiced but rarely scientifically documented. The behavioural development before release (e.g. regarding hunting skills) is particularly important for ensuring animals are self-sustaining after release. We document the rehabilitation and release of three confiscated cheetah (Acinonyx jubatus) cubs and one leopard (Panthera pardus) cub, which were taken from the wild in Botswana. The animals were raised with minimal human contact and the development of their hunting skills was observed and assisted by limited pre-release training. After release, all animals were monitored and data showed they successfully hunted, with behavioural patterns similar to wild conspecifics. All established stable home ranges at the release site. Home ranges of the cheetahs ranged from 44 to $121 \mathrm{~km}^{2}$, travelling primarily during the early morning and evening, ranging from 4.5 to $9.4 \mathrm{~km} /$ day. While the leopard survived and probably reproduced within a stable home range $\left(449 \mathrm{~km}^{2}\right)$, all three cheetahs were shot within 7 months of release. Therefore, although orphaned large felids can successfully hunt after release using appropriate rehabilitation techniques, they face the same human-carnivore conflicts of their wild counterparts. Our study demonstrates the indispensable but commonly neglected need for post-release monitoring in wildlife rehabilitation.
\end{abstract}

Key words: Acinonyx jubatus, behavioural development, de-habituation, home range, orphan, Panthera pardus, post-release monitoring, pre-release training, wildlife rehabilitation.

\section{INTRODUCTION}

The International Wildlife Rehabilitation Council defines wildlife rehabilitation as 'the process of providing aid to injured, orphaned, displaced, or distressed wild animals in such a way that they may survive when released to their native habitats' (http://www.iwrc-online.org). Wildlife rehabilitation in Africa gained popularity in the 1960s after the release of orphaned lions (Panthera leo) in Kenya, followed by other orphaned large felids such as cheetahs (Acinonyx jubatus) and leopards (Panthera pardus) (Williams 2009). With an increasing frequency of news about rehabilitation programmes being established, one would expect large felid rehabilitation to have become a well

\footnotetext{
*To whom correspondence should be addressed.
}

E-mail: amhouser3@yahoo.com established scientific field. A literature database search of peer-reviewed articles on carnivores, published in scientific journals between 1970 and 2010 (available from http://www.carnivoreconservation.org), using the search string (rehab* or orphan*), resulted in only 23 hits. Of the eight articles actually dealing with rehabilitation, most (six) were on bears (reviewed by Clark 2009), while none were on large felids. The lack of scientific information raises concerns that spending scarce financial resources will not be cost effective for conservation organizations committed to the rehabilitation and release of large felids. The apparent lack of scientific monitoring, evaluation and reporting in such release programmes (Gusset 2009) also raises concerns regarding the postrelease welfare of the orphaned animals involved. 
While there is little scientific information on the rehabilitation and release of orphaned cheetahs or leopards, Pettifer (1981a) reports on the release of captive-bred cheetahs (also see Pettifer 1981b; Rowe-Rowe 1992; Hunter 1999; Marker et al. 2003; Hayward et al. 2007a,b; Marnewick et al. 2009). Conflict with humans was the biggest threat to their survival. The same appears to be true for translocated leopards (Hayward et al. 2007a,b,c; Weilenmann et al. 2010) and many other large carnivores (Hayward \& Somers 2009). Rehabilitation thus needs to be carefully implemented with reference to behavioural development and human habituation before release, as these developments can affect behavioural responses later in life (Bekoff 1989). In release programmes, captivebred carnivores were found to have lower postrelease survival rates than wild-caught individuals (Jule et al. 2008). This may be due to underdeveloped hunting skills (as a result of not having the opportunity to learn from experienced conspecifics) and habituation to humans before release (Bauer 2005).

The global status of the cheetah has declined from approximately 100000 in 1900 to less than 15000 in the 1990s (Marker 1998). Botswana holds the second largest population of cheetahs (Klein 2007) and is likely to be a stronghold for leopards too. Yet, as elsewhere, both species are threatened by human-carnivore conflicts (Schiess-Meier et al. 2007; Selebatso et al. 2008; Gusset et al. 2009). This conflict occasionally causes incidents of orphaned cheetahs and leopards being confiscated by the Department of Wildlife and National Parks (DWNP). With a successful rehabilitation programme, these animals could be used to re-establish cheetahs and leopards in areas where populations of the two species have declined or disappeared, as has been proposed for orphans of other species (McNutt et al. 2008).

The present study is among the first to scientifically document the process of rehabilitating and releasing orphaned wild-caught individuals from two large felid species, with behavioural monitoring before and after release. A particular focus is on the behavioural development of hunting skills and limiting habituation to humans in the orphaned animals before release, as having self-sustaining animals after release may serve as a pragmatic criterion for rehabilitation success (Gusset 2009). Furthermore, post-release monitoring gives an indication of whether the study animals could estab- lish successfully in their new environment. The results of this study should be applicable to the rehabilitation of other orphaned animals, including those bred or raised in captivity and intended for release.

\section{METHODS}

\section{Study areas and holding facilities}

The study was conducted from January 2005 to November 2009, with rehabilitation of study animals taking place at the Jwaneng base camp $\left(24^{\circ} 31^{\prime} \mathrm{S}\right.$, $\left.24^{\circ} 43^{\prime} \mathrm{E}\right)$ of Cheetah Conservation Botswana (CCB), which is located at Jwana Game Reserve in southern Botswana. The cheetahs were released in the Tuli area at Kwalata Game Farm (9000 ha) in eastern Botswana, which is located along the

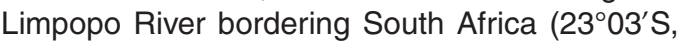
$\left.27^{\circ} 52^{\prime} \mathrm{E}\right)$. This fenced game farm contained abundant wild prey and predators, such as leopards, brown hyaenas (Hyaena brunnea) and lions, were occasionally present. The leopard was released in an unfenced wildlife management area in southern Botswana $\left(24^{\circ} 39^{\prime} \mathrm{S}, 23^{\circ} 04^{\prime} \mathrm{E}\right)$ with abundant wild prey. Lions were occasionally present and DWNP was consulted to ensure that the release site had no territorial leopards already resident in the area.

Study animals were kept in custom-made holding facilities during rehabilitation. All holding facilities were of the same design - they were divided into a lockdown area $(19 \times 10 \mathrm{~m})$ with a small shelter containing a wooden platform, an alleyway $(1 \times$ $10 \mathrm{~m}$ ) with guillotine gates to control access, and a larger enclosure area $(20 \times 30 \mathrm{~m})$ that contained $2-3$ trees, shrubs and grasses. The use of guillotine gates and two adjoining pens enabled separation of the animals from humans during feeding and cleaning of the pen. The enclosure was surrounded by shade cloth to reduce visual contact with humans. Human interaction with the study animals was kept to a minimum throughout the rehabilitation process (for further details, see Houser 2008).

The pre-release enclosure used for habituating the cheetahs to their release site was a 100 ha enclosure with natural vegetation and no other predators on Kwalata Game Farm. The enclosure was stocked predominantly with impalas (Aepyceros melampus) and tsessebes (Damaliscus lunatus), with the former being a preferred prey species of cheetahs (Hayward et al. 2006). The enclosure had three electric wires that kept the cheetahs in. However, it allowed free movement of smaller 
Table 1. Time lines of rehabilitation and release of the three cheetahs (A1, G2 and D3) and the leopard.

\begin{tabular}{lccccccc}
\hline & $\begin{array}{c}\text { Months in } \\
\text { captivity before } \\
\text { confiscation }\end{array}$ & $\begin{array}{c}\text { Age when } \\
\text { acquired } \\
\text { (months) }\end{array}$ & $\begin{array}{c}\text { Months in } \\
\text { holding } \\
\text { facility }\end{array}$ & $\begin{array}{c}\text { Months in } \\
\text { pre-release } \\
\text { enclosure }\end{array}$ & $\begin{array}{c}\text { Age when } \\
\text { released } \\
\text { (months) }\end{array}$ & $\begin{array}{c}\text { Months in } \\
\text { release area }\end{array}$ & $\begin{array}{c}\text { Age when } \\
\text { killed } \\
\text { (months) }\end{array}$ \\
\hline A1 & 1 & 3 & 16 & 8 & 27 & 4 & 31 \\
G2 & 1 & 3 & 16 & 8 & 27 & 5 & 32 \\
D3 & 2 & 6 & 15 & 8 & 29 & 7 & 36 \\
Leopard & 4 & 6 & 18 & N/A & 24 & $>19$ & N/A \\
\hline
\end{tabular}

animals in and out of the enclosure through warthog (Phacochoerus africanus) holes.

\section{Study animals and procedures}

Cheetahs. Three wild-born cheetahs (3-6 months of age) were confiscated by DWNP and presented to CCB between January and February 2005 (see Table 1 for details). In the wild, cubs remain in the den until two months old and do not accompany their mother on hunts until at least four months of age (Caro 1994); thus, the cheetahs were unlikely to have witnessed hunts by the time of capture.

During the time spent in the holding facility, the cheetahs were fed $1.5-3.0 \mathrm{~kg}$ of meat with bone per day, with a calcium supplement of $5 \mathrm{~g} /$ day.
They were fed once daily, with 1 starvation day per week. As they grew older (12-15 months) the quantity and timing of feedings was varied (with 1-3 starvation days) to simulate varying hunting success in the wild. During their stay in the holding facility, the cheetahs were introduced to various dead and live prey animals, including poultry, rabbits and wild prey (Table 2), to induce hunting behaviour and allow recognition of prey once released.

After 16 months, the subadult cheetahs were transported to the designated release site at Kwalata Game Farm. The cheetahs were each fitted with a VHF collar (Telonics) and placed in the 100 ha pre-release enclosure (Table 1). Behav-

Table 2. Responses of the three cheetahs to the introduction of live and dead prey in the holding facility.

\begin{tabular}{|c|c|c|c|c|}
\hline \multicolumn{2}{|c|}{ Hunting episode } & \multicolumn{3}{|c|}{ Individual } \\
\hline & & D3 & $\mathrm{A} 1$ & G2 \\
\hline \multirow[t]{4}{*}{1} & Age & $11 / 14$ months & 9/11 months & 9/11 months \\
\hline & Prey & Live chickens & Live chickens & Live chickens \\
\hline & Successfully killed prey? & Yes & Yes & Yes \\
\hline & Observations & $\begin{array}{l}\text { Killed prey with cranial } \\
\text { puncture bite }\end{array}$ & $\begin{array}{l}\text { Killed prey by pulling } \\
\text { it apart }\end{array}$ & $\begin{array}{l}\text { Killed prey by pulling it } \\
\text { apart }\end{array}$ \\
\hline \multirow[t]{4}{*}{2} & Age & 14 months & 12 months & 12 months \\
\hline & Prey & Live rabbit & Live rabbit & Live rabbit \\
\hline & Successfully killed prey? & Yes & Yes & No \\
\hline & Observations & Killed prey immediately & Killed prey immediately & $\begin{array}{l}\text { Lost interest once prey } \\
\text { stopped moving }\end{array}$ \\
\hline \multirow[t]{4}{*}{3} & Age & 21 months & 19 months & 19 months \\
\hline & Prey & Dead impala & Dead impala & Dead impala \\
\hline & $\begin{array}{l}\text { Successfully recognised } \\
\text { and consumed prey? }\end{array}$ & Yes & Yes & Yes \\
\hline & Observations & $\begin{array}{l}\text { Immediately attacked and } \\
\text { consumed prey }\end{array}$ & $\begin{array}{l}\text { Immediately attacked and } \\
\text { consumed prey }\end{array}$ & $\begin{array}{l}\text { Immediately attacked and } \\
\text { consumed prey }\end{array}$ \\
\hline \multirow[t]{4}{*}{4} & Age & $\geq 22$ months & $\geq 20$ months & $\geq 20$ months \\
\hline & Prey & Injured impalas & Injured impalas & Injured impalas \\
\hline & Successfully killed prey? & Yes & Yes & Yes \\
\hline & Observations & $\begin{array}{l}\text { Prey killed by suffocation } \\
\text { and consumed }\end{array}$ & $\begin{array}{l}\text { Prey killed by suffocation } \\
\text { and consumed }\end{array}$ & $\begin{array}{l}\text { Prey killed by suffocation } \\
\text { and consumed }\end{array}$ \\
\hline
\end{tabular}


ioural observations, focusing on hunting and feeding behaviour, were recorded from a vehicle every $15 \mathrm{~min}$ from 6:00 a.m. to 7:00 p.m. for 48 consecutive days.

After 7 months in this enclosure, the cheetahs' VHF collars were replaced with GPS collars (Televilt), and they were released into the game farm. Visual observations were obtained from a vehicle parked at distance to limit habituation, and observations were recorded approximately once every 7-10 days to monitor their condition, including feeding and vigilance behaviour at kills, for approximately 7 months after release.

Leopard. In October 2006, a wild-born female leopard, about 6 months old, was confiscated by DWNP and placed in the care of CCB (Table 1). The leopard was given the same diet as the cheetahs. Body condition and behaviour of the leopard, which was extremely elusive from the beginning, were monitored through motion cameras set within the holding facility. The leopard was provided with enrichment by hiding food and providing scent trails throughout the pre-release period, and was given pre-release hunting training similar to the cheetahs by introducing her to various small live prey.

After 18 months in this holding facility (Table 1), the leopard was transported to the designated release site in the wildlife management area. The leopard was released in April 2008 without being kept in a pre-release enclosure first. Such a hard release was used as it was considered that her more developed hunting abilities (as evidenced by regular kills in the holding facility; see below) would allow the leopard to survive in the wild (in contrast to the cheetahs in this study, for which a soft release was used). The leopard's health was checked and a satellite collar (Sirtrack) fitted, with limited direct monitoring after release.

\section{Spatial and statistical analysis}

The animal movement extension (Hooge \& Eichenlaub 2000) in conjunction with ArcView GIS 3.2 (Environmental Systems Research Institute Inc.) and Ranges 7, version 2.2 (Anatrack Ltd.) were used for spatial analyses. Using locations recorded every 24 hours, the individual's home range and core area were calculated with the $95 \%$ and $50 \%$ fixed kernel method, respectively (Worton 1989), using a least-squares crossvalidation smoothing factor. For comparison, the $95 \%$ and $50 \%$ peeled minimum convex polygons (MCP) were also calculated (Jennrich \& Turner
1969), using the harmonic mean to remove $5 \%$ and $50 \%$ of outliers, respectively. Home range size was deemed accurate if, when calculated by the $95 \%$ peeled MCP method, the area-observation plots reached an asymptote.

Up to six locations per 24 hours for each cheetah and two locations per 24 hours for the leopard were used to calculate daily distances travelled after release. SPSS 11.0 (SPSS Inc.) was used for statistical analyses. Kolmogorov-Smirnov tests revealed a normal distribution of the data's residuals. In cheetahs, individual differences in behaviour before release and daily distance travelled after release were thus assessed using $\chi^{2}$ analysis and one-way ANOVA, respectively. Significance was measured at $P<0.05$ and all tests were two-tailed.

\section{RESULTS}

\section{Introduction to live prey and hunting behaviour in the holding facility}

\section{Cheetahs}

Table 2 shows that the cheetahs successfully learned to hunt small and large wild prey. Judged by how quickly they showed interest by stalking or chasing prey, and their abilities to effectively catch prey and kill it, the cheetahs' hunting skills were observed to improve with experience.

\section{Leopard}

When introduced to live prey at 9 months of age, the leopard responded by killing small prey shortly after introduction into the enclosure. Remains of mongooses, birds and lizards naturally entering the holding facility were repeatedly found throughout the time in captivity. The leopard also responded readily to the enrichment provided.

\section{Cheetah hunting behaviour in the pre-release enclosure}

Of the 24 observed hunts in the pre-release enclosure, D3, A1 and G2 were successful on $55.5 \%$ $(n=9), 44.4 \%(n=9)$ and $16.6 \%(n=6)$ of attempts that they led, respectively. In most observed hunts $(75.0 \%)$ more than one cheetah was involved. Combined hunting success was $41.7 \%$ (10 kills in 24 observed hunts). In the first two weeks entire carcasses were consumed over several days, with the cheetahs resting in the vicinity of the carcasses. Two weeks after release the cheetahs would only eat on carcasses the day it was hunted. 
Table 3. Percentage of time spent showing different behaviours of the three cheetahs in the pre-release enclosure. Differences in the number of observed behaviours among the three individuals were assessed using $\chi^{2}$ analysis.

\begin{tabular}{lccccrr}
\hline & D3 (\%) & A1 (\%) & G2 (\%) & Combined (\%) & $\chi^{2}$-value & $P$-value \\
\hline Observational & 16.5 & 17.7 & 18.7 & 17.8 & 1.29 & 0.523 \\
Resting & 41.9 & 43.8 & 45.9 & 44.1 & 1.76 & 0.415 \\
Locomotive & 30.3 & 22.4 & 21.6 & 24.0 & 16.70 & $<0.001$ \\
Playing & 2.1 & 3.7 & 3.5 & 3.3 & 4.16 & 0.125 \\
Hunting & 0.4 & 1.9 & 2.1 & 1.6 & 9.43 & 0.009 \\
Exploratory & 2.4 & 1.6 & 1.5 & 1.7 & 2.47 & 0.291 \\
Contact & 0.9 & 1.7 & 1.8 & 1.6 & 2.67 & 0.264 \\
Feeding & 5.0 & 7.1 & 4.8 & 5.7 & 6.21 & 0.040 \\
Kills & 0.5 & 0.1 & 0.2 & 0.2 & 4.14 & 0.126 \\
No. of observations & 759 & 1152 & 1160 & 3071 & & \\
\hline
\end{tabular}

They mainly hunted impalas (66.6\%) and steenbok (Raphicerus campestris) $(20.5 \%)$, primarily adults $(61.5 \%)$ regardless of sex $(n=39$ hunts observed and kills found). Analyses of prey remains in scats revealed that they also fed on smaller birds, lagomorphs, rodents and one black-backed jackal (Canis mesomelas). Their hunting and killing techniques became increasingly refined, including stalking of prey and improved strangulation technique. For example, the first few kills of the cheetahs showed punctures in the neck, with tearing of the throat; however, within four weeks, cheetah kills showed no visible signs of strangulation, a hunting technique usually shown by wild cheetahs (Caro 1994). Most hunting and feeding behaviour $(64.1 \%)$ was observed from 4:00 a.m. to 11:00 a.m. ( $n=39$ hunts observed and kills found). The cheetahs did not rely on chasing prey into the fence, as most kills $(65.0 \%)$ were made away from the fence ( $n=24$ kills). They were never artificially fed in the pre-release enclosure.

The time spent showing different behaviours in the pre-release enclosure was broken down into nine categories (Table 3), with D3, A1 and G2 being observed for 120.5 hours, 186.3 hours and188.6 hours, respectively. The cheetahs spent most of their time resting (44.1\%), with significant differences among the three individuals in locomotive, hunting and feeding behaviour (Table 3 ). The individual (G2) with the lowest hunting success (see above) showed the most hunting but the least feeding behaviour.

\section{Post-release behaviour of rehabilitated animals}

\section{Cheetahs}

After release into the game farm, all three cheetahs immediately separated and continued to live and hunt alone (Fig. 1a), with individually variable but stable home range and core area sizes (Table 4). The cheetahs moved mainly from 4:00 a.m. to 11:00 a.m. (47.2\%). There was a significant difference in the mean daily distance travelled among the three individuals (one-way ANOVA: $F=$ 14.46, $P<0.001$; Table 4). The individual (G2) that showed the least locomotive behaviour before release (Table 3 ) also moved the least after release.

The cheetahs only ate the main portions (thigh, shoulder or ribs) of the kills and left within 1-4 hours; they did not return to kills or stay in the area. All three cheetahs showed heightened vigilance at kills after release. After 2 months of being alone on

Table 4. Home ranges (95\% kernel and minimum convex polygon [MCP]), core areas (50\% kernel and MCP) and daily distances travelled of the three cheetahs (D3, A1 and G2) and the leopard after release.

\begin{tabular}{|c|c|c|c|c|c|c|c|}
\hline & \multirow[t]{2}{*}{ No. of days } & \multicolumn{2}{|c|}{ Kernel $\left(\mathrm{km}^{2}\right)$} & \multicolumn{2}{|c|}{$\operatorname{MCP}\left(\mathrm{km}^{2}\right)$} & \multicolumn{2}{|c|}{ Daily movement (km) } \\
\hline & & $95 \%$ & $50 \%$ & $95 \%$ & $50 \%$ & Mean \pm S.E. & Maximum \\
\hline D3 & 178 & 44.1 & 3.1 & 96.4 & 18.7 & $6.3 \pm 0.4$ & 28.1 \\
\hline $\mathrm{A} 1$ & 113 & 121.4 & 23.6 & 70.1 & 16.8 & $9.4 \pm 0.7$ & 25.9 \\
\hline G2 & 140 & 60.5 & 4.0 & 78.3 & 1.1 & $4.5 \pm 0.6$ & 25.4 \\
\hline Leopard & 590 & 449.3 & 46.7 & 716.9 & 104.2 & $3.8 \pm 0.1$ & 17.1 \\
\hline
\end{tabular}


(a)

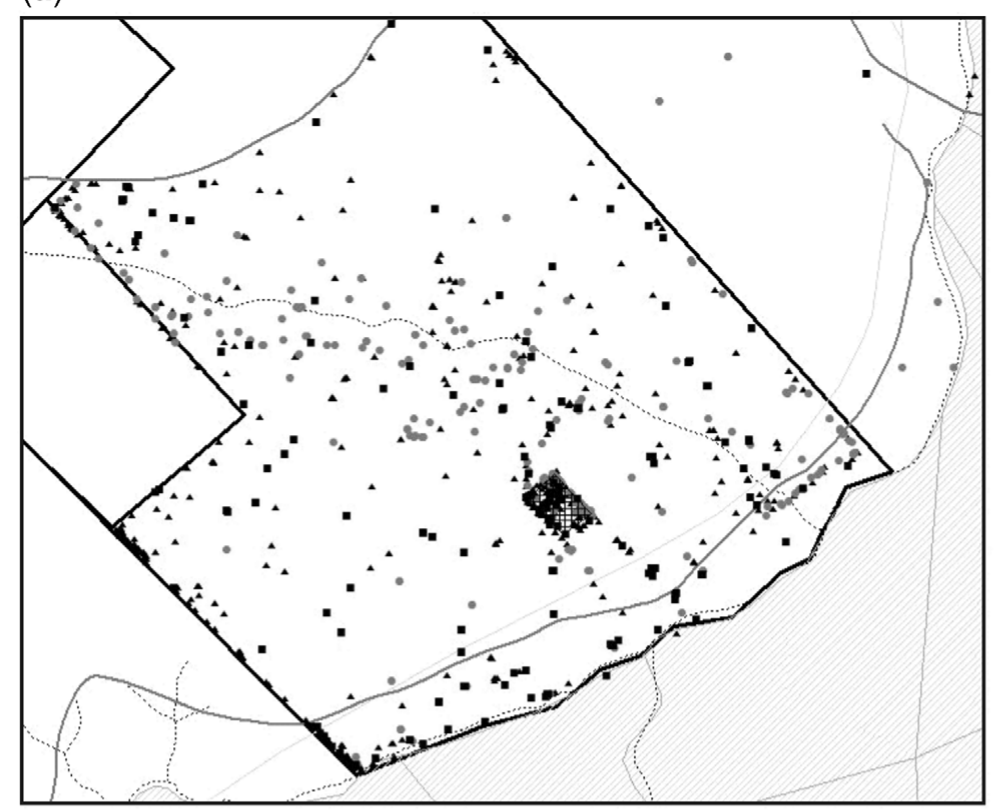
3 6 9 12 Kilometers

(b)

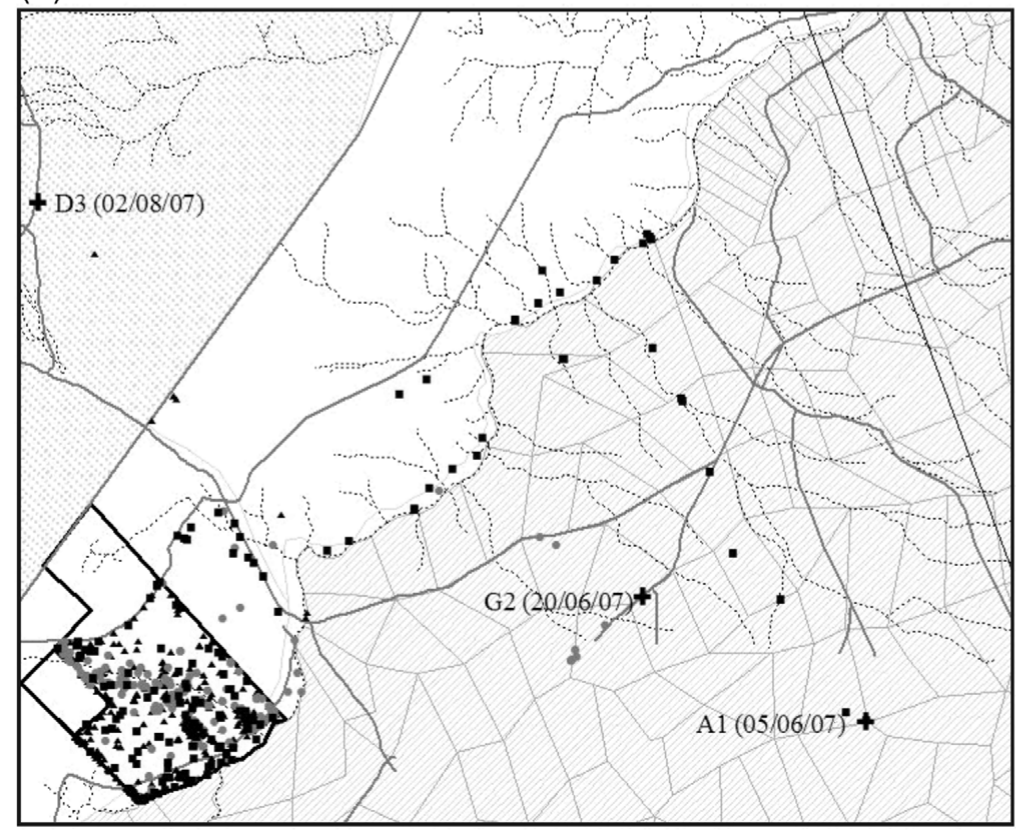

+ Death Locations

- A1

- G2

- D3

Roads Rivers

$\square$ Kwalata Game Farm

Botswana farm land

Freehold Farms

Pastoral/A rable/Residential

South Africa farm land

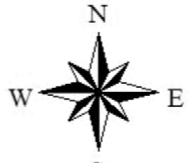

40 Kilometers

Fig. 1. Locations of the three cheetahs (a) within the game farm including the 100 ha pre-release enclosure and (b) after leaving the game farm, with date and place of death indicated for each individual. 


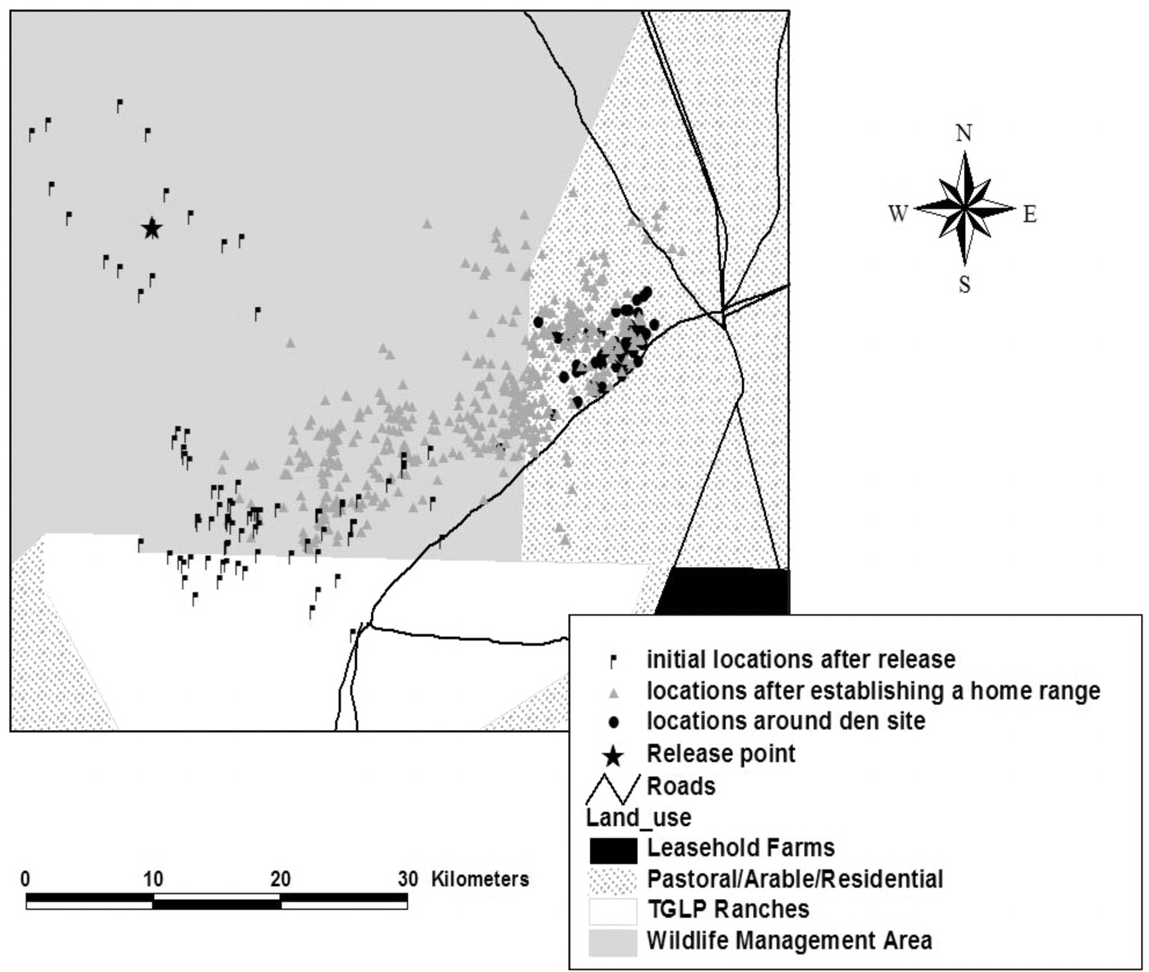

Fig. 2. Locations of the leopard initially after release and after establishing a home range, with spatially concentrated locations indicating the probable den site.

the game farm, the male cheetah (D3) was observed to show sexual interest in the two females when they were in oestrus.

\section{Leopard}

After release into the wildlife management area, the leopard initially travelled $32 \mathrm{~km}$ southeast of the release site and spent a total of nine days on neighbouring TGLP (tribal grazing land policy) ranches that lie inland from the border of South Africa (Fig. 2). After the initial 1.5 months and excluding the possible denning period, the leopard settled and established a home range primarily within the wildlife management area $58.7 \%$ of the time (Table 4, Fig. 2), and $38.7 \%$ of the time in the pastoral/arable/residential land-use areas. The leopard was apparently able to hunt successfully.

\section{Fate of rehabilitated animals}

\section{Cheetahs}

After four months on the game farm (Table 1), one female cheetah (A1) left the area when the river dropped low, facilitating escape. She first travelled through neighbouring farms along the
Limpopo River and then crossed into South Africa (Fig. 1b). A1 was shot on a game farm during a professional hunt $55 \mathrm{~km}$ away from the release site 12 days after leaving.

The other female cheetah (G2) left after 5 months on the game farm two days after A1 was killed, followed A1's path along the Limpopo River, crossing into South Africa (Fig. 1b), and was shot from the road along the fence of a game farm 12 days later. Neither A1 nor G2 were reported by managers of farms where cheetah locations were recorded to have taken livestock or threatened people before their death.

After 7 months on the game farm, the male cheetah (D3) left and travelled $37 \mathrm{~km}$ north (Fig. 1b). D3 was shot and killed one day after leaving the game farm. It is unclear why the cheetahs left the game farm; however, a lion was on the farm during the month the females left. Two wild male cheetahs were observed outside of the perimeter fence the month before the male left the farm.

\section{Leopard}

When the study was completed in November 2009, the leopard was still alive 19 months after 
release (Table 1). Spatially concentrated locations in August/September 2009 indicated a possible den site (Fig. 2), with strong scent of leopard urine coming from the burrow where GPS points were concentrated. The leopard was not reported to DWNP to have taken livestock nor did she approach people when ranging in livestock grazing areas.

\section{DISCUSSION}

The present study on the rehabilitation and release of orphaned large felids was specifically targeted at improving reintroduction success, through the behavioural development of hunting skills and by limiting habituation to humans. The environment in captivity before release, including pre-release training, is decisive for post-release survival in many species (Kleiman 1989; Somers \& Gusset 2009). In our study, the assisted development of hunting skills worked (cf. Pettifer 1981a), without the animals having the opportunity to learn from the mother (cf. Gusset et al. 2006) and without supplementary feeding after release.

In the cheetahs, hunting, killing and feeding behaviours (including prey selection, hunting success and vigilance at kills) were similar to wild conspecifics (Caro 1994). This suggests that the limited pre-release training employed (Houser 2008) can be recommended for use elsewhere, taking into account observed individual and species-specific differences in behavioural development. Post-release ranging behaviour of the three cheetahs was comparable to wild conspecifics, including daily movement and activity patterns (Hayward \& Slotow 2009). The cheetahs' home range sizes were within the range of figures recorded for wild cheetahs elsewhere: from 34 to $161 \mathrm{~km}^{2}$ in South Africa (Hunter 1999) and from 800 to $1500 \mathrm{~km}^{2}$ in Namibia (Marker-Kraus et al. 1996). However, the cheetahs' home ranges were considerably smaller on average than those of their wild conspecifics in nearby areas (Houser et al. 2009). Durant (2000) found that cheetahs tend to have larger home ranges when there is competition with larger predators. The cheetahs might have left the release area due to the recent arrival of a lion in their range or reported sightings of two male cheetahs outside of the perimeter fence of the game farm. Alternatively, it is possible that the female cheetahs left the game farm due to lack of suitable breeding mates. The game farm was well-stocked with prey so it is unlikely that a lack of food was the determining factor for their departure.
The leopard showed similar movement and home range patterns to wild conspecifics, with a large home range characteristic of more arid areas (Marker \& Dickman 2005; Hayward et al. 2007a; Weilenmann et al.2010) with low densities of prey (Hayward et al. 2009), including the initial roaming behaviour typical for translocated carnivores (Somers \& Gusset 2009).

The animals in this study showed signs of mating behaviour (cheetahs) and possible reproduction (leopard), and their rehabilitation, in terms of being self-sustaining, establishing a home range and showing reproductive behaviour, could be classified as successful. However, although the cheetahs were raised with minimal human contact to limit habituation and never approached people (or their livestock) after release, they could not avoid humans at all times within this landscape matrix of livestock and game farms (cf. Pettifer 1981a), with a fatal outcome for the animals involved. In such areas, human persecution is the main cause of death in adult cheetahs (Marker et al. 2003), and conflict with livestock farms (Klein 2007) and game ranches (Pettifer 1981a) is believed to be a major threat to wild cheetah populations.

Although numerous attempts to translocate and release cheetahs have been undertaken (Pettifer 1981a, b; Rowe-Rowe 1992; Hunter 1999; Marker et al. 2003; Hayward et al. 2007a,b; Marnewick et al.2009, B. Schumann, pers. comm.), most have been unsuccessful due to human-induced mortality. The ranging behaviour that exposed the cheetahs to fatal contact with people could be restricted by predator-proof perimeter fencing (Hayward et al. 2007a; Gusset et al. 2008; Marnewick et al. 2009), but this also limits the natural exchange of animals among sites (Hayward \& Kerley 2009). Pre-release aversive conditioning (Griffin et al. 2000) and total separation from humans while in the holding facility during feeding and cleaning times, and using large protected areas as release sites such as with the leopard in this study, might thus be indicated in future cheetah rehabilitation attempts.

Many conservation organizations are currently committed to the rehabilitation and release of orphaned large felids. While the rehabilitation and subsequent release of orphaned animals attract donor funding, post-release monitoring is expensive, and thus commonly neglected (Hunter 1999; Gusset 2009). Consequently, the fate of released animals is often unknown and where it is known it is frequently poor (e.g. Weilenmann et al. 2010). In 
our study, the running costs involved in the rehabilitation and release of the four animals over a four-year period was approximately US $\$ 4000$ per animal per year (excluding costs for vehicle and holding facilities) for long-term care (cf. Marnewick et al. 2009). The benefit of being able to release self-reliant predators in areas where they have been eradicated, or are genetically isolated, is more cost-effective and desirable than relying on captive cheetah facilities. Given these considerable expenses, scientific monitoring, evaluation and reporting in such release programmes should be improved to underpin management decisions with scientific evidence (Gusset 2009).

Many conservation organizations probably would have announced the rehabilitation in our study a qualified success, as without post-release monitoring it is likely the animals would have been assumed alive, and the rehabilitation methods resulted in self-sufficient individuals surviving and reproducing in the wild. However, our results suggest that, although a rehabilitation attempt can be successful in terms of producing self-sustaining animals, ultimately rehabilitation must also consider the human-related threats that these animals may face after release.

\section{CONCLUSION}

Our study shows that orphaned large felids can be successfully released using appropriate rehabilitation techniques, and these animals could be used to re-establish populations of the respective species that have declined or disappeared. However, post-release survival depends on mitigating threatening factors, such as human ignorance and illegal killing, which need to be addressed by continued outreach programmes. Applied behaviour research (Pettifer 1995; Somers \& Gusset 2009) and post-release monitoring will be key components in developing wildlife rehabilitation into an evidence-based field in animal welfare and conservation.

\section{ACKNOWLEDGEMENTS}

This study was supported by Cheetah Conservation Botswana, especially Rebecca Klein and Kyle Good. Thanks are due to Debswana for allowing our project to be carried out at Jwana Game Reserve and to Kwalata Game Farm for providing the pre-release enclosure and prey for the cheetahs to learn hunting skills. Thabang Segaetsho and Mark Bing are gratefully acknowledged for their help in the rehabilitation and release of the leopard. We are grateful to Andre van der Kooi and Faan Coetzee for their efforts within the legal system by continuing to seek justice and build cases on illegal poaching of endangered species. We also thank Botswana's Department of Wildlife and National Parks for support and permission to conduct this study and rehabilitation work (permit number OP46/1 C11(103), 03/02/2003).

\section{REFERENCES}

BAUER, G.B. 2005. Research training for releasable animals. Conserv. Biol.19: 1779-1789.

BEKOFF, M. 1989. Behavioral development of terrestrial carnivores. In: J.L. Gittleman (Ed.), Carnivore behavior, ecology, and evolution (pp. 89-124). Cornell University Press, Ithaca.

CARO, T.M. 1994. Cheetahs of the Serengeti plains: group living in an asocial species. University of Chicago Press, Chicago.

CLARK, J.D. 2009. Aspects and implications of bear reintroduction. In: M.W. Hayward \& M.J. Somers (Eds), Reintroduction of top-order predators (pp. 126-145). Wiley-Blackwell, Oxford.

DURANT, S.M. 2000. Living with the enemy: avoidance of hyenas and lions by cheetahs in the Serengeti. Behav. Ecol. 11: 624-632.

GRIFFIN, A.S., BLUMSTEIN, D.T. \& EVANS, C.S. 2000. Training captive-bred or translocated animals to avoid predators. Conserv. Biol. 14: 1317-1326.

GUSSET, M. 2009. A framework for evaluating reintroduction success in carnivores: lessons from African wild dogs. In: M.W. Hayward \& M.J. Somers (Eds), Reintroduction of top-order predators (pp. 307-320). Wiley-Blackwell, Oxford.

GUSSET, M., SLOTOW, R. \& SOMERS, M.J. 2006. Divided we fail: the importance of social integration for the re-introduction of endangered African wild dogs (Lycaon pictus). J. Zool., Lond. 270: 502-511.

GUSSET, M., RYAN, S.J., HOFMEYR, M., VAN DYK, G., DAVIES-MOSTERT, H.T., GRAF, J.A., OWEN, C., SZYKMAN, M., MACDONALD, D.W., MONFORT, S.L., WILDT, D.E., MADDOCK, A.H., MILLS, M.G.L., SLOTOW, R. \& SOMERS, M.J. 2008. Efforts going to the dogs? Evaluating attempts to re-introduce endangered wild dogs in South Africa. J. Appl. Ecol 45: 100-108.

GUSSET, M., SWARNER, M.J., MPONWANE, L., KELETILE, K. \& McNUTT, J.W. 2009. Human-wildlife conflict in northern Botswana: Livestock predation by endangered African wild dog Lycaon pictus and other carnivores. Oryx 43: 67-72.

HAYWARD, M.W., HOFMEYR, M., O'BRIEN, J. \& KERLEY, G.I.H. 2006. Prey preferences of the cheetah (Acinonyx jubatus) (Felidae: Carnivora): morphological limitations or the need to capture rapidly consumable prey before kleptoparasites arrive? J. Zool., Lond. 270: 615-627.

HAYWARD, M.W., ADENDORFF, J., O'BRIEN, J., SHOLTO-DOUGLAS, A., BISSETT, C., MOOLMAN, L.C., BEAN, P., FOGARTY, A., HOWARTH, D., SLATER, R. \& KERLEY, G.I.H. 2007a. Practical considerations for the reintroduction of large, terres- 
trial, mammalian predators based on reintroductions to South Africa's Eastern Cape Province. Open Conserv. Biol. J. 1: 1-11.

HAYWARD, M.W., ADENDORFF, J., O'BRIEN, J., SHOLTO-DOUGLAS, A., BISSETT, C., MOOLMAN, L.C., BEAN, P., FOGARTY, A., OWARTH, D., SLATER, R.\& KERLEY, G.I.H. 2007b. The reintroduction of large carnivores to the Eastern Cape, South Africa: an assessment. Oryx 41: 205-214.

HAYWARD, M.W., ADENFORFF, J., MOOLMAN, L.C., HAYWARD, G.J. \& KERLEY, G.I.H. 2007c. The successful reintroduction of leopard Panthera pardus to the Addo Elephant National Park. Afr. J. Ecol. 45: 103-104.

HAYWARD, M.W., HAYWARD, G.J., DRUCE, D.J. \& KERLEY, G.I.H. 2009. Do fences constrain predator movements on an evolutionary scale? Home range, food intake and movement patterns of large predators reintroduced to Addo Elephant National Park, South Africa. Biodivers. Conserv. 18: 887-904.

HAYWARD, M.W. \& KERLEY, G.I.H. 2009. Fencing for conservation: Restriction of evolutionary potential or a riposte to threatening processes? Biol. Conserv. 142: 1-13.

HAYWARD, M.W. \& SLOTOW, R. 2009. Temporal partitioning of activity in large African carnivores: tests of multiple hypotheses. S. Afr. J. Wildl. Res. 39: 109-125.

HAYWARD, M.W. \& SOMERS, M.J. (Eds), 2009. Reintroduction of top-order predators. Wiley-Blackwell, Oxford.

HOOGE, P.N. \& EICHENLAUB, B. 2000. Animal movement extension to ArcView, ver. 2.0. USGS Alaska Science Center, Anchorage.

HOUSER, A.M. 2008. Spoor density, movement and rehabilitation of cheetahs in Botswana. M.Sc. thesis, University of Pretoria.

HOUSER, A.M., BOAST, L.K. \& SOMERS, M.J. 2009. Home range use of free-ranging cheetah on farm and conservation land in Botswana. S. Afr. J. Wildl. Res. 39: 11-22.

HUNTER, L. 1999. Large felid restoration: lessons from the Phinda Resource Reserve, South Africa, 19921999. Re-introd. News 18: 9-11.

JENRICH, R.I. \& TURNER, F.B. 1969. Measurement of non-circular home range. J. Theor. Biol.22:227-237.

JULE, K.R., LEAVER, L.A. \& LEA, S.E.G. 2008. The effects of captive experience on reintroduction survival in carnivores: a review and analysis. Biol. Conserv. 141: 355-363.

KLEIMAN, D.G. 1989. Reintroduction of captive mammals for conservation: Guidelines for reintroducing endangered species into the wild. BioScience 39: 152-161.

KLEIN, R. 2007. Status report for the cheetah in Botswana. Cat News Special Issue 3: 14-21.

MARKER-KRAUS, L.L., KRAUS, D., BARNETT, D, HURLBUT, S. 1996. Cheetah survival on Namibian farmlands. Cheetah Conservation Fund, Windhoek.

MARKER, L. 1998. Current status of the cheetah (Acinonyx jubatus). In: B.L. Penzhorn (Ed.), Proceedings of a symposium on cheetahs as game ranch animals (pp. 1-17). South African Veterinary Association, Onderstepoort.

MARKER, L., DICKMAN, A.J., MILLS, M.G.L. \& MACDONALD, D.W. 2003. Aspects of the management of cheetahs, Acinonyx jubatus jubatus, trapped on Namibian farmlands. Biol. Conserv. 114:401-412.

MARKER, L. \& DICKMAN, A.J. 2005. Factors affecting leopard (Panthera pardus) spatial ecology, with particular reference to Namibian farmlands. S. Afr. J. Wildl. Res. 35: 105-115.

MARNEWICK, K., HAYWARD, M.W., CILLIERS, D. \& SOMERS, M.J. 2009. Survival of cheetahs relocated from ranchland to fenced protected areas in South Africa. In: M.W. Hayward \& M.J. Somers (Eds), Reintroduction of top-order predators (pp. 282-306). Wiley-Blackwell, Oxford.

McNUTT, J.W., PARKER, M.N., SWARNER, M.J. \& GUSSET, M. 2008. Adoption as a conservation tool for endangered African wild dogs (Lycaon pictus). S. Afr. J. Wildl. Res. 38: 109-112.

PETTIFER, H.L. 1981a. The experimental release of captive-bred cheetah (Acinonyx jubatus) into the natural environment. In: J.A. Chapman \& D. Pursley (Eds), Worldwide furbearer conference proceedings (pp. 1001-1024). Worldwide Furbearer Conference, Frostburg.

PETTIFER, H.L. 1981b. Aspects of the ecology of cheetahs (Acinonyx jubatus) on the Suikerbosrand Nature Reserve. In: J.A. Chapman \& D. Pursley (Eds), Worldwide furbearer conference proceedings (pp. 1121-1142). Worldwide Furbearer Conference, Frostburg.

PETTIFER, H.L. 1995. The social behaviour and rehabilitation of carnivores. In: B.L. Penzhorn (Ed.), Proceedings of the SASOL symposium on wildlife rehabilitation (pp. 95-100). South African Veterinary Association, Onderstepoort.

ROWE-ROWE, D.T. 1992. The carnivores of Natal. Natal Parks Board, Pietermaritzburg.

SCHIESS-MEIER, M., RAMSAUER, S., GABANAPELO, T. \& KÖNIG, B. 2007. Livestock predation Insights from problem animal control registers in Botswana. J. Wildl. Manage. 71: 1267-1274.

SELEBATSO, M., MOE, S.R. \& SWENSON, J.E. 2008. Do farmers support cheetah Acinonyx jubatus conservation in Botswana despite livestock depredation? Oryx 42: 430-436.

SOMERS, M.J. \& GUSSET, M. 2009. The role of social behaviour in carnivore reintroductions. In: M.W. Hayward \& M.J. Somers (Eds), Reintroduction of top-order predators (pp. 270-281). Wiley-Blackwell, Oxford.

WEILENMANN, M., GUSSET, M., MILLS, D.R., GABANAPELO, T. \& SCHIESS-MEIER, M. 2010. Is translocation of stock-raiding leopards into a protected area with resident conspecifics an effective management tool? Wildl. Res. 37: 702-707.

WILLIAMS, L. 2009. Pride \& Joy. Afr. Geogr. 17(7): 30-34.

WORTON, B.J. 1989. Kernel methods for estimating the utilization distribution in home-range studies. Ecology 70: 164-168. 